\title{
A POÉTICA DO ABISMO EM ÁGUA NEGRA DE LÍVIA NATÁLIA
}

\author{
CÁSSIA DA SILVA ${ }^{1}$ \\ MARIA LÚCIA PESSOA SAMPAIO ${ }^{2}$ \\ SEBASTIÃO MARQUES CARDOSO ${ }^{3}$
}

\author{
Universidade do Estado do Rio Grande do Norte, Departamento de Educação \\ Campus Avançado Prof ${ }^{a}$ Maria Elisa de Albuquerque Maia \\ 59900000 - Pau dos Ferros, RN - Brasil \\ cassia silv@hotmail.com, malupsampaio@hotmail.com , \\ sebastiaomarques@uol.com.br
}

\begin{abstract}
Resumo. O trabalho aqui exposto se constitui como uma análise dos poemas "Rastro"; "Memória filogenética" e "Mnemografias" (2011) da autora Lívia Natália. Com base na concepção de "abismo" desenvolvida por Edouard Glissant (2011), enfoca-se nessa análise os abismos presentes nos poemas na tentativa de que se possa refletir sobre como estes abismos, configurados em traços de memória coletiva (HALBWACHS, 2003) de um povo, se estruturam no labor estético da obra de Natália (2011) tornando-se assim, arma de luta contra o apagamento do sofrimento passado de um grupo social. Neste artigo, além da discussão sobre o conceito de abismos e exemplificações a partir de determinadas cenas metaforizadas dos textos, também analisa-se as funções que essas cenas exercem no entendimento amplo dos poemas.
\end{abstract}

Palavras-chave: Teoria Literária; Literatura afro-brasileira; Livia Natália; memória; identidade.

\begin{abstract}
The work presented here constitutes an analysis of the poems "Rastro"; "Memória filogenética" and "Mnemografias" (2011) by the author Livia Natália. Based on the "abyss" conception developed by Edouard Glissant (2011), this analysis focuses on the abyss present in the poems in an attempt to reflect on how these chasms, configured in traces of collective memory (HALBWACHS, 2003) a people, are structured in the aesthetic work of Natalia's work (2011) thus becoming a weapon of struggle against the erasure of the past suffering of a social group. In this article, besides the discussion about the concept of abysses and exemplifications from certain metaphorical scenes of the texts, also the functions that these scenes exert in the broad understanding of the poems are analyzed.
\end{abstract}

Keywords: Literary Theory; Afro-Brazilian Literature; Livia Natália; memory; identity.

\footnotetext{
${ }^{1}$ Doutoranda em Letras na Universidade do Estado do Rio Grande do Norte, UERN.

${ }^{2}$ Doutora em Educação pela UFRN. Docente e pesquisadora (graduação e pós-graduação) da UERN.

${ }^{3}$ Doutor em Teoria e História Literária pela Unicamp. Docente permanente do Departamento de Letras Estrangeiras (DLE- FALA) e dos Programas de Pós-Graduação em Letras (PPGL) e Ciências da Linguagem (PPCL) da UERN.
} 
Quando leio uma poeta mulher negra, geralmente escuto um grito. Um grito que fala de outros tempos e outras dores que se repetem ainda hoje.

Prates, 2016.

\section{INTRODUÇÃO}

Ao iniciar esse texto tendo no título a palavra abismo, há de se pensar na carga semântica que essa palavra trará aos leitores. Abismo sinônimo de sorvedouro, de voragem, de queda, de ruína, pode até, inicialmente, trazer à tona a ideia de precipício, de pessimismo à poética que se propõe analisar. Mas, longe disso, o abismo aqui se assemelhará a um desvelamento das profundezas humanas, quando essas são possíveis de se revelarem nos poemas.

Diante disso, a pesquisa aqui proposta visa a análise dos "abismos" (GLISSANT, 2011) construídos no trabalho estético dos poemas do livro Água Negra, de Lívia Natália. Lançada em 2011, esta obra é uma coletânea poética que destrói a concepção secular da mulher negra como personagem coadjuvante ou/e figurante e a torna senhora de sua própria história. Sem a imersão em preconceitos de uma sociedade branca, racista, sexista, homofóbica, a autora abala a noção ainda existente de submissão e inferioridade historicamente reservada às escritoras negras (ADÚN, 2011).

Numa proposta de trabalho como este, de análise de "abismos" que se presentificam nos poemas de uma autora contemporânea, mais se enfatiza a preocupação de Barthes (2005): a linguagem literária não pode ser apenas analisada como cenário luxuoso da realidade social, passional que preexiste a ela. A literatura, através da travessia da linguagem, tornase perseguidora do abalamento dos conceitos essenciais da nossa cultura e, agindo assim, politicamente - ao ilustrar e professar que não há linguagem inocente na prática da linguagem integral - é que a literatura torna-se revolucionária.

Concebendo a perspectiva da crítica integral à obra literária e analisando os poemas de Água negra, pode-se afirmar que a estrutura da obra segue um viés poético contemporâneo, de rimas e versos livres nos quais a mulher negra, tida, historicamente, como mero objeto de uso e abuso masculino, ora explorada sexualmente, ora máquina insaciável de prazer, é revestida de essência feminina e tem seu corpo devolvido no processo de labor estético (ADÚN, 2011, p. 02).

Sendo este um desafio, o interesse pelo tema da pesquisa em questão tem embasamento em motivos de âmbito social, ou seja, provém da constatação de que, através dos registros dos abismos, como símbolos poéticos, o leitor torna-se capaz de conhecer mais a fundo a história de um povo que se relaciona com o eu lírico e este, através de suas memórias (metaforizadas nos poemas), expõe o que toca a fundo e angustia o ser humano.

\section{ABISMOS CONSTRUÍDOS PELA MEMÓRIA COLETIVA}

Em face do termo que intitula a obra mais famosa de Maurice Halbwachs, A memória coletiva (2003) depara-se com um conceito que referencia recordações significativas para 
um determinado grupo social. Por ser construída socialmente, ela é responsável por compartilhar, entre um povo, fenômenos de opinião pública e acontecimentos significativos de uma determinada sociedade. Assim,

a "memória coletiva" (é) aquela que recompõe magicamente o passado. Entre essas duas direções da consciência coletiva e individual desenvolvem-se as diversas formas de memória, cujas formas mudam conforme os objetivos que elas implicam. Isto não significa, certamente, que os espíritos estejam, entre si, separados uns dos outros, mas que a combinação dos grupos coletivos onde estão engajados esses espíritos define múltiplas experiências do tempo. (DUVIGNAUD, 2003, p. 07; grifos nossos)

Diante dessa conceituação de memória coletiva, reconstituída por Duvignaud no prefácio da obra de Halbwachs, já é possível refletir sobre os abismos que se formam na memória dos povos contemporâneos a partir das reminiscências sociais que experimentaram, de um passado não tão distante, como as torturas de uma época de escravidão.

Quando se concebe o entendimento do que comporta a memória coletiva dos povos, se afirma a existência de recordações de acontecimentos representativos para um coletivo: como ocorreram e permanecem ocorrendo e como outros foram combatidos.

Esses eventos, vivenciados em outrora e recordados no presente, são, como afirma Halbwachs (2003) "marcos sociais" e é a partir desses que se limitam e se escrevem o que interessa a um determinado grupo.

Nesse âmbito, a linguagem se constitui como ferramenta fundamental para a instauração desses marcos sociais, pois esta é o espaço social das ideias, é pela linguagem que se mantém e se comunica os sentidos da memória, é através dela que se interioriza a cultura e seus significados, ademais, a linguagem é uma produção social e consequentemente, cultural (HALBWACHS, 2003).

A memória coletiva, concretizada e exposta através da linguagem, tão transpassada de inúmeros fatos sociais e recordações de épocas diversas, não pode ser compreendida como regular e cronológica. Os marcos sociais se misturam na memória, os abismos de épocas passadas se interlaçam, se chocam, se fundem:

nossa busca da dimensão temporal não será, pois nem harmoniosa nem linear. Ela caminhará em uma polifonia de choques dramáticos, tanto ao nível do consciente como do inconsciente, entre dados e tempos disparatados, descontínuos, cuja ligação não é evidente. A harmonia majestosa não prevalece aqui, mas sim (enquanto para nós a história a ser feita não tiver reencontrado o passado até aqui desconhecido) a busca inquieta e quase sempre caótica. (GLISSANT, 1981, p. 194)

Nesse âmbito de "busca inquieta e quase sempre caótica", é que se instauram - pelo poder da memória coletiva - os abismos visitados e revisitados, expostos e reexpostos, subjetivos e concretizados nas produções literárias de poetas e prosadores que usam a linguagem como elo de lembranças das vivências diversas de sua comunidade, por isso: 
a literatura nestas condições pode não ser um objeto de deleite, nem de tranquilidade. Ora isto coloca o problema daquele para quem a obra é escrita. Uma tendência generosa de nossas produções é de colocar-se de saída "à mão" dos que sofrem a alienação social ou cultural. Tendência legítima na medida em que agir sobre concretamente sobre os dados desta alienação. Mas a constatação quase elementar das carências, se é preciosa em um combate quotidiano, pode também impedir que se perceba estruturas mais profundas de opressão, que, contudo, é preciso revelar. Esta exposição, paradoxalmente, não se faz a cada vez na evidência e na clareza [...] Acontece que a obra não seja escrita para alguém, mas para desmontar os mecanismos complexos da frustração e das variedades infinitas da opressão. (GLISSANT, 1981, p. 194)

Nessa afirmação de Glissant (1981) reside a ambivalência da obra literária de militância (como é Água Negra): uma escrita que possa ser entendida pelos "que sofrem a alienação" e que, ao mesmo tempo, não é claramente exposta, pois faz uso de ferramentas da linguagem que funcionam de forma complexa em prol dos desmontes da "opressão". Assim é constituída a catarse do abismo (expurgação do que se sente ao lembrar de tormentos vividos outrora por um povo), numa obra engajada. Os abismos expostos são retomados da memória de grupo social, memória esta que não pode ser apagada, não o deve ser, pois é a partir dela que se milita pelo não-retorno a nenhum tipo de submissão de um povo sob outro.

A experiência do abismo está no abismo e fora dele [...] Os povos que então se constituíram, mesmo que tivessem esquecido o abismo, mesmo que não conseguissem imaginar o tormento daqueles que aí pereceram, não deixaram de tecer uma vela (um véu) com a qual, não regressando à Terra-Anterior, se ergueram nesta terra aqui, súbita e estupefacta. [...] E assim o desconhecido-absoluto, que era a projeção do abismo, [...] tornou- se por fim conhecimento. (GLISSANT, 2011, p. 18)

É assim, em diálogo com Glissant, que se percebe que a experiência do abismo transita para o conhecimento: projetar um abismo é descortinar tormentos de caráter social de um dado grupo em uma determinada época. Desvelar tais tormentos é também conhecer o que forma uma sociedade e como se constitui um povo e suas descendências.

\section{QUANDO NA AGGA NEGRA SE REFLETEM OS ABISMOS}

Na contramão das regularidades dos discursos racistas que, infelizmente, ainda subsistem no século XXI, teremos, na atualidade, os discursos de reafirmação identitária da mulher negra, esses que ganharão força nos debates de gêneros e identidade, mas que serão sentidos intimamente e sensivelmente na fruição e análise dos textos literários.

É revigorante e motivador acompanhar a reelaboração da mulher negra através dos escritos de Conceição Evaristo, Alzira Rufino, Esmeralda Ribeiro, Elizandra Souza e agora, Lívia Natália, uma grande alegria. Felicidade maior ainda em saber que Água Negra será lido na contramão das estatísticas. (ADÚN, 2011, p. 02) 
As estatísticas, da qual fala Adún, são aquelas visivelmente expostas nas obras de análise e crítica literária, que são perceptíveis não pela presença e sim pela ausência; ausência da voz da mulher negra, ausência do discurso literário dessa mulher.

A invisibilidade de escritoras negras no mercado literário não quer dizer que inexista uma produção fora do mainstream das grandes editoras assim como a invisibilidade de nomes na literatura brasileira não significa que elas não tenham existido. (ADÚN, 2011, p. 02)

Essa invisibilidade a que Adún se refere pode ser analisada como uma marca de regularidade discursiva que circunda o campo da identidade feminina negra, já que o discurso é composto também por silêncios (FOUCAULT, 2010). Não se atentar a essa ausência da mulher negra nos escritos literários (e até mesmo de crítica e análise literária) é o mesmo que ignorar as vozes que gritam por ser ouvidas nas entrelinhas do não escrito (do que foi, por imposição, calado).

Se o não-dito forma o discurso literário, o dito e o escrito o concretizam. E, na exposição de um dizer coletivo, é impossível não perceber, nos versos de Lívia Natália, "o abismo [...], todo o oceano, todo o mar, por fim afagado com doçura pelos prazeres da praia, um enorme começo, só ritmado por essas grilhetas cobertas de verdete" (GLISSANT, 2011, p. 18).

Esses abismos, que perpassam a maior parte dos poemas da obra Água Negra, estão desde o título do livro metaforizados e banhados em águas que fluem ao encontro de uma memória coletiva.

Para desencavar o caos da história imposta. Lá onde as técnicas de expressão não são inocentes. Explorar o caos da memória (ofuscada, alienada ou reduzida a um repertório de referências naturais) não pode se fazer na clareza da exposição consecutiva. A produção de textos deve ser por sua vez produção de história, não enquanto desencadeia um acontecimento, mas enquanto ressuscita ao nível da consciência um panorama esquecido. A exploração não é analítica, mas criadora. A exposição tremula diante desta criação opaca, deste conteúdo contraditório cuja convergência não é dada de saída. (GLISSANT, 1981, p.194)

Os abismos expressos "sem inocência", como afirma Glissant (1981) - e presentes em Água Negra - não se expõem com a função de analisar algo ou alguém, estes seguem a missão da obra de arte: servem à criação. Assim, "ressuscitam" fatos que não podem ser apagados e nem recontados em linguagem objetiva, pois seus campos semânticos estão para além da superfície denotativa das palavras, mergulham nas profundezas da subjetividade humana.

\section{"RASTRO" DE "MEMÓRIA FILOGENÉTICA" EM "MNEMOGRAFIAS"}

O poema de abertura da obra Água Negra (2011), "Rastro" permite, a partir de sua composição em três estrofes, uma leitura que (I) pluraliza a humanidade; (II) a coloca em seu lugar de fato: ao lado dos outros componentes do universo e formada por estes 
componentes: "somos todos feitos da poeira de estrelas" (NATÁLIA, 2011, p. 13); (III) para, por fim, singularizar o sofrimento de um eu-lírico, parte de toda essa composição.

Há, na trama retecida da minha alma, um ressoar silente como o das estrelas, a que chamo angústia, apesar da poeira luminosa e viva que trago debaixo dos pés

(NATÁLIA, 2011, p. 13)

Como parte integrante da humanidade e formado também por "poeira de estrelas", o eulírico desse poema revela ao leitor o que traz como abismo de alma: a "angústia", metaforizada em uma antítese de som silencioso "como o das estrelas", por ser, o eu poético, constituído por elas.

A angústia (o abismo poético) nesse poema é encarada como componente paradoxal, pois ao mesmo tempo que se faz em "um ressoar silente", é confrontada com a "poeira luminosa e viva" dos rastros do eu lírico.

Um sentimento de angústia que se instaura no mesmo campo semântico do desespero é uma forma de catarse dos abismos que não podem ser anestesiados, pois servem à função do engajamento poético-político do poema:

À margem dos combates políticos, o escritor tenta demonstrar as engrenagens de sua inserção, mesmo se sua prática corre o risco de introduzir por um tempo uma forma de desespero, que não é demissão. Esgotar este desespero, do qual terminamos, no cotidiano, por não mais ter consciência, é reavivar a ferida e escapar às anestesias do mesmo. Não há nisso nenhum pessimismo, mas a reserva última de quem escreve e quer bater-se em seu terreno. (GLISSANT, 1981, p. 190)

É dessa forma que, aos poucos, os abismos poéticos vão se instaurando na obra de Lívia Natália, mergulhados nas antíteses que formam os sentimentos angustiantes do interior humano e, como afirma Glissant (acima) reabrem feridas que, mesmo antes cicatrizadas, não são esquecidas integralmente pois deixaram marcas profundas na "trama retecida da alma".

Já o poema "Memória Filogenética", traz desde o título a retomada da ideia de memória coletiva tão promulgada por Halbwachs (2013), já que a significação do adjetivo "filogenética" abrange o entendimento da epistemologia da palavra; assim:

filogenia (ou filogênese) (grego: phylon $=$ tribo, raça e genetikos $=$ relativo à gênese $=$ origem) é o termo comumente utilizado para hipóteses de relações evolutivas (ou seja, relações filogenéticas) de um grupo de organismos, isto é, determinar as relações ancestrais entre espécies conhecidas (ambas as que vivem e as extintas). (PEPULIN, 2011, p. 44)

Dessa forma, o título se remete a uma memória que existe a partir das relações entre o eu lírico e seus ancestrais, memória essa que será, no poema, metaforizada em todo o corpo do eu lírico para mostrar os abismos que guardam em si "estrelas caídas", "cantos carcomidos", "crimes e pecados sonhados": 
Meu corpo, parco limite terrestre,

é todo feito do sobejo das estrelas caídas.

Soterradas, elas exploram os subterrâneos de meu afeto,

iluminam minhas vilezas,

descortinam o que há de pérfido,

e vão.

Revelam os cantos carcomidos pela espera,

apontam crimes e pecados

apenas sonhados.

(NATÁLIA, 2011, p. 23)

Nessa primeira estrofe, já é possível perceber a presença dos abismos construídos numa memória que se metaforiza, no primeiro verso, em "corpo", numa tentativa de concretização daquilo que tanto se subjetiva: as lembranças (também metaforizadas em "estrelas caídas").

Sendo corpo, a memória se constrói a partir de vocábulos que evocam lembranças de teor cético: "Sobejo", "estrelas caídas", "soterradas", "subterrâneos", "pérfidos", "vão", "carcomidos", "crimes e pecados". São essas palavras que remetem aos abismos da memória do eu lírico e revelam reminiscências - "estrelas caídas" - que parecem expor de forma involuntária a memória do eu poético: "descortinam o que há de pérfido" (NATÁLIA, 2011, p. 23).

Já que têm atitudes próprias, as estrelas agem ("exploram", "iluminam", descortinam; "revelam"; "apontam") e trazem à tona o que outrora foi "apenas sonhado", mas que no presente não pode ser esquecido, pois, como afirma Glissant (2011, p. 18), "os abismos são o nosso próprio inconsciente, povoados de fugidias memórias. Depois desenha essas novas costas, onde depomos as nossas chagas estriadas de alcatrão, as nossas bocas ensanguentadas e os nossos gritos silenciados".

As estrelas ainda voltam a aparecer como símbolo da "memória" no oitavo poema da obra de Lívia Natália, "Mnemografias", novamente o título antecipa a temática das lembranças que, como abismos, tomarão as entrelinhas do poema.

A expressão "mnemografia" é na verdade um neologismo formado pela junção de "mnemo" que se remete a algo "mnemônico", ou seja, "relativo à memória; [...] fácil de conservar na memória; que ajuda a memória" (BUENO, 1996, p. 435) e "grafia", termo que se relaciona à escrita. Assim, o título do poema prenuncia uma escrita que se conserva na memória; a escrita de situações memoráveis, metaforizadas (novamente) em estrelas:

As estrelas são apenas memória de luz.

Seu brilho melancólico e alto

é o arremedo triste do que se foi.

Um eco para sempre repetido

- e perdido.

(NATÁLIA, 2011, p. 27)

A primeira estrofe do poema retoma a simbologia das estrelas que, assim como as lembranças, brilham tristemente e longe ("melancólico e alto") trazendo o som "do que 
se foi". O abismo que se instaura na memória desse eu lírico se configura como um "um eco para sempre repetido".

Toda a poesia então que se seguirá será como uma barca, o que Glissant $(2011$, p. 17) assim descreve:

uma barca, segundo a tua poética, não tem ventre, uma barca não engole, não devora, uma barca pilota-se a céu aberto. O ventre dessa barca dissolve-te, precipita-se num não mundo onde gritas. Essa barca é uma matriz, poço-matriz. Geradora do teu brado. Produtora também de toda a unanimidade por vir. Porque se estás só nesse sofrimento, partilhas o desconhecido com alguns, que ainda não conheces. Essa barca é a tua matriz, um molde, que, no entanto, te expulsa. Grávida tanto de mortos como de vivos.

Nessa poética, caracterizada como barca e "geradora do brado" do eu lírico, as lembranças (estrelas, astros) retomam uma memória coletiva em que um grito se faz presente: "algo de mim grita/ nestes astros caídos" (NATÁLIA, 2011, p. 27).

Esse grito remete aos que se foram, pois é: "algo que se arrasta/ na poeira das ausências" (NATÁLIA, 2011, p. 27), não se apresenta no poema em tom pessimista, ao contrário, todas as lembranças, essas "mnemografias", que formam os abismos de memórias do eu lírico, assim como "estrelas (que) são apenas memórias de luz" (NATÁLIA, 2011, p. 27), iluminam o presente, refletem o que não pode ser apagado, tornam-se visíveis e "como brilham!" (NATÁLIA, 2011, p. 27).

\title{
CONCLUSÃO
}

\begin{abstract}
Minha fé é negra, /e minha alma enegrece a terra /no ilá /que de minha boca escapa. /Sou uma arvore negra de raiz nodosa. /Sou um rio de profundidade limosa e calma. /Sou a seta e seu alcance antes do grito. /E mais o fogo, o sal das águas, a tempestade /e o ferro das armas. /E ainda luto em horas de sol obtuso /Nas encruzilhadas. (NATALIA, 2011, p. 33)
\end{abstract}

Todos os conceitos de Glissant (1981 e 2011) caminham ao encontro de uma experiência poética em que os abismos fazem da linguagem - por vezes ameaçada - o instrumento de combate de um autor (GLISSANT, 1981). Nesse âmbito, a poetisa Lívia Natália, em Água Negra (2011), compõe um eu lírico que expõe os abismos de sua memória coletiva (HALBWACHS, 2003) como uma arma de luta contra o apagamento da dor de seus antepassados.

Reviver, na poesia, os abismos é conhecer a si e ao outro, é conhecer a história de um povo, é relacionar-se conjuntamente com os acontecimentos que formam a memória de um grupo social, é, como afirma Glissant (2011, p.19): "não só conhecimento particular, apetite, sofrimento e fruição de um povo particular, não só isso, mas o conhecimento do Todo, que aumenta com a experiência do abismo e que no Todo liberta o saber da Relação". 


\section{REFERÊNCIAS}

ADÚN, Mel. Água negra é um mergulho. Em: NATÁLIA, Lívia. Água Negra. Salvador: EPP Publicações e Publicidades, 2011.

BARTHES, R. O rumor da língua. $2^{\mathrm{a}}$. ed. São Paulo: Martins Fontes, 2004.

BUENO, F. da Silveira. Dicionário de Língua Portuguesa. São Paulo: FTD; LISA, 1996.

DUVIGNAUD, Jean. Prefácio. Em: HALBWACHS, Maurice. Memória Coletiva. Trad. Bras.. São Paulo: Centauro, 2003.

FOUCAULT, M. As regularidades discursivas. Em: FOUCAULT, M. A arqueologia do saber. Rio de Janeiro: Forense Universitária, 2005.

GLISSANT, E. A barca aberta. Em: Poética da Relação. Lisboa Sextante Editora, 2011.

GLISSANT, E. Le discours antillais. In: Le Même et le Divers. Paris: Seuils, 1981. p. 190-201.

HALBWACHS, M. Memória Coletiva. Trad. Bras. São Paulo: Centauro, 2003.

NATÁLIA, Lívia. Água Negra. Salvador: EPP Publicações e Publicidades. 2011.

PEPULIM, Maria Elizabeth Horn. TV Digital Aberta Brasileira: o adolescente como usuário efetivo da interatividade via TV. Dissertação. Mestrado em Engenharia e Gestão do Conhecimento, Universidade Federal de Santa Catarina, 2011.

PRATES, Lubi. Mulheres poetas, vibrantes porém ignoradas. 2016. Disponível em https://outraspalavras.net/blog/mulheres-poetas-vibrantes-porem-ignoradas/. Acesso em $10 \mathrm{fev}$. 2017.

Artigo recebido em: maio de 2018.

Aprovado e revisado em: nov. de 2018.

Publicado em: dezembro de 2019.

Para citar este texto:

DA SILVA, Cássia; SAMPAIO, Maria Lúcia Pessoa; CARDOSO, Sebastião Marques. A poética do abismo em Água Negra de Lívia Natália. Entremeios [Revista de Estudos do Discurso, ISSN 2179-3514, on-line, www.entremeios.inf.br], Seção Estudos, Programa de Pós-Graduação em Ciências da Linguagem (PPGCL), Universidade do Vale do Sapucaí (UNIVÁS), Pouso Alegre (MG), vol. 18, p. 141-149, jan. - jun. 2019.

DOI: http://dx.doi.org/10.20337/ISSN2179-3514revistaENTREMEIOSvol18pagina141a149 